\title{
LA POTESTAD LEGISLATIVA, LOS TIPOS DE LEY Y SUS RELACIONES INTERNAS EN EL DERECHO NACIONAL
}

\author{
Eduardo Cordero Quinzacara*
}

\begin{abstract}
RESUMEN
Este trabajo hace una revisión de los tipos de leyes previstos en nuestro ordenamiento jurídico, con el objeto de establecer su naturaleza y los principios que han de regir en los casos de conflictos de normas, teniendo presente los criterios sentados por la doctrina nacional y la jurisprudencia del Tribunal Constitucional de Chile. El autor sostiene que no existe un concepto sustantivo de los tipos legales y que las relaciones entre estas leyes se deben resolver, por regla general, conforme al principio del procedimiento, sin perjuicio de que en algunos casos también baya una posible aplicación del principio de jerarquía.
\end{abstract}

POTESTAD LEGISLATIVA - TIPOS DE LEYES - CONFLICTOS DE NORMAS

Legislative power, types of law and internal relations in the national law

\begin{abstract}
This research reviews the types of laws in the Chilean legal system in order to establish its nature and principles which should solve the problem of clash of norms, keeping in mind the criteria of legal doctrine and the jurisprudence of the Chilean Constitutional Court. The author maintains the inexistence of substantive concept of the types of laws and that the relationship between these laws must be resolved, as a rule, under the principle of the procedure or, in some cases, the principle of hierarchy.
\end{abstract}

LEGISLATIVE POWER - TYPES OF LAW - CLASH OF NORMS

* Abogado, Doctor en Derecho, Profesor de Derecho administrativo de la Pontificia Universidad Católica de Valparaíso, Valparaíso, Chile. eduardo.cordero@ucv.cl. Este trabajo es parte de una investigación financiada por FONDECYT referida al proyecto "El ordenamiento jurídico chileno y el nuevo sistema de fuentes" $\mathrm{N}^{\circ} 1080619$.

Artículo recibido el 19 de marzo de 2010 y aceptado para su publicación por el Comité Editorial el 28 de mayo de 2010 . 


\section{AnteCedentes Generales: DEL MONismo LEGislativo}

\section{A LA PLURALIDAD DE LEYES}

$\mathrm{L}$ a entrada en vigencia de la Constitución de 1980, ocurrida el 11 de marzo de 1981, implicó un cambio sustancial en el sistema de fuentes del derecho nacional, especialmente respecto de la ley, cuyo protagonismo en los ordenamientos jurídicos desde el siglo XIX es indiscutible.

La ley ocupa un lugar central dentro de la articulación del sistema jurídico, en la medida que es un instrumento que proyecta las normas y previsiones constitucionales, prescribe y disciplina de forma sustantiva el contenido medular del ordenamiento jurídico y define, a su vez, los márgenes de actuación de las normas administrativas, especialmente aquellas que emanan de la potestad reglamentaria. Sin embargo, desde fines del siglo XIX esta fuente fue perdiendo las características y, por tanto, la función que tenía asignada en el marco del Estado liberal de Derecho, llegando a ser una norma contingente y de coyuntura que estaba lejos de los caracteres de generalidad, abstracción y permanencia con los cuales fue concebida por las ideas liberales ${ }^{1}$. Esto llegó a tal punto en nuestro país, que el Gobierno y el Congreso plantearon seriamente la posibilidad de revisar esta situación y establecer un sistema que le diera a la ley un carácter normativo, general, de marco o de bases, con la finalidad de recuperar esta función articuladora de las demás normas y lograr un mejor juego y coordinación con la regulación reglamentaria ${ }^{2}$.

La Constitución de 1980 innova de forma sustantiva sobre la materia yendo aún más lejos, en la medida que impone a la ley el deber de regular las materias estableciendo normas de carácter general y obligatoria que estatuyan las bases esenciales de un ordenamiento jurídico (artículo $63 \mathrm{~N}^{\circ} 20$ ), de tal forma que la regulación de materias de contenido singular o concreto debe estar expresamente señalada por la Constitución, pues constituye una excepción a dicha regla general ${ }^{3}$. Pero donde se produce un cambio de proporciones es en relación con los tipos de leyes que consagra la Carta de 1980, que rompe en alguna medida con la idea unitaria de ley que hasta dicha época había reinado en nuestro ordenamiento jurídico. Así, pasamos de la ley a una pluralidad de tipos legales: las leyes interpretativas de la Constitución, las leyes orgánicas constitucionales, las leyes

${ }^{1}$ Véase Cordero Quinzacara, E., "Los principios y reglas que estructuran el ordenamiento jurídico chileno", en Ius et Praxis, vol. 15, No 2, 2009, pp. 14-18.

${ }^{2}$ Este es un problema común a todos los ordenamientos comparados, como da cuenta la amplia bibliografía que existe sobre la materia. Véase Díez-Picazo, L. M., "Concepto de ley y tipos de ley. ¿Existe una noción unitaria de ley en la Constitución Española?”, en Revista Española de Derecho Constitucional, Año 8, $\mathrm{N}^{\circ} 24$, septiembre-diciembre, 1988, pp. 47-93. En el caso de Chile es interesante la discusión que se dio durante la tramitación de la reforma constitucional de la Ley $\mathrm{N}^{\circ} 17.284$, cuyo eje central estuvo centrado en la posibilidad de establecer lo que se conoce como leyes normativas o de bases. Los antecedentes de la tramitación de esta ley se pueden consultar en Andrade Geywitz, C., Elementos de Derecho constitucional chileno, $2^{a}$ ed., Santiago, Editorial Jurídica de Chile, 1971, pp. 472-494.

${ }^{3}$ En este sentido nos hemos pronunciado en otro trabajo. Véase Cordero Quinzacara, E., "El sentido actual del dominio legal y la potestad reglamentaria”, en Revista de Derecho, Pontificia Universidad Católica de Valparaíso, XXXII, Semestre I, 2009, pp. 409-440. 
de quórum calificado y las leyes ordinarias. Para tal efecto, el Constituyente de 1980 agrupó un conjunto de materias que deben ser objeto de regulación legal, para posteriormente diversificarla, sobre la base de la importancia relativa que el propio Constituyente les asigna, y termina estableciendo un procedimiento de aprobación, modificación y derogación más agravado según la valoración que se ha hecho de las mismas.

El diseño de un sistema diversificado de leyes surge en su época como una propuesta interesante y novedosa, en la medida que permitió solucionar dos problemas fundamentales en un ordenamiento jurídico: a) Evitar que la Constitución estuviese demasiado recargada en la regulación de materias y contenidos de detalle o reglamentarios, aunque fuesen de una importancia político-institucional innegable; y b) Establecer un sistema en cuya virtud estas materias fueran reguladas por una norma infraconstitucional, pero que los procedimientos de elaboración y aprobación no fuesen los mismos a los cuales se sujeta una ley simple u ordinaria, dada la importancia que se les ha asignado a las mismas.

Habiendo transcurrido casi dos décadas de la plena implementación de este sistema, lo cierto es que todavía existen algunas dificultades y problemas que no han encontrado en la doctrina y en la jurisprudencia una respuesta del todo adecuada, especialmente en lo que dice relación con los principios o reglas que se deben aplicar al momento de establecer las relaciones o vínculos que se producen entre estas leyes y la forma en que se deben resolver los eventuales conflictos o antinomias que se han presentado entre ellas. En tal sentido, este trabajo tiene por objeto volver sobre el tema y hacer una propuesta que permita colocar en la discusión algunos criterios para abordarlo.

Para estos efectos, comenzaremos por analizar la posibilidad de conceptualizar y determinar el ámbito material de estas leyes (2) para luego proponer algunos criterios destinados a resolver las relaciones y conflictos que se puedan presentar entre ellas (3).

\section{Concepto y Sustantividad de las Leyes EN El DERECHO CHILENO}

Nuestra Constitución no entrega un concepto de Ley. Esto no significa que en ella no existan algunos elementos que pueden llevar a delinear sus características y alcances, ya sea de carácter sustancial (generalidad, obligatoriedad, regulación de bases esenciales) o formal (órgano competente y procedimiento) ${ }^{4}$. Como bien ha dicho Parejo Alfonso, "el

\footnotetext{
${ }^{4}$ El concepto de ley ha sido uno de los temas que mayor interés ha despertado en la doctrina durante buena parte del siglo XX, a partir del fenómeno descrito anteriormente que transformó a esta norma en una regulación contingente y singular. A este respecto, véase Díez-Picazo (n. 2), pp. 47-93; García de Enterría, E. y Fernández, T. R., Curso de Derecho administrativo, vol. I, $10^{\mathrm{a}}$ ed., Madrid, Civitas, 2000, pp. 113-115; Garrido Falla, Fernando, "Tratado de Derecho administrativo", vol. I, 10 ed., Madrid, Tecnos, p. 198 y ss.; Garrorena Morales, A. El lugar de la ley en la Constitución española, Madrid, Centro de Estudios Constitucionales, 1980; De Otto, Ignacio, Derecho constitucional. Sistema de fuentes, $2^{\mathrm{a}}$ ed., Barcelona, Ariel, 1988, pp. 102-106; Rubio Llorente, Francisco, F. "Rango de ley, fuerza de ley, valor de ley. Sobre el problema del concepto de ley en la Constitución”, en Revista de Administración Pública, vol. I, N ${ }^{\text {os. } 100-102, ~ e n e r o-d i c i e m b r e, ~} 1983$, pp. 417-432; Santamaría Pastor, J. A., Fundamentos de Derecho administrativo, Madrid, Centro de Estudios
} 
concepto de Ley es hoy una decantación de la evolución histórica en la que se funden los conceptos políticos (mandato emanado de la soberanía popular) y jurídico-sustantivo: norma abstracta y general; formal: norma emanada del órgano constitucionalmente competente, con las solas, pero importantes, modificaciones inducidas por la conversión del Estado democrático de Derecho materialmente primero en Estado administrativo y formalmente luego en Estado social [...]"5.

Una situación similar ha sucedido con los diversos tipos de leyes que incorpora la Carta de 1980, pues no existe un concepto constitucional, de manera que la doctrina y la jurisprudencia han hecho una suerte de síntesis con los elementos que le entrega la propia Carta Fundamental, en donde la materia regulada constituye el eje central al cual se le incorporan aspectos de quórum y procedimiento. En todo caso, como tendremos ocasión de explicar más adelante, esto no excluye la posibilidad de que algunos tipos de leyes puedan ser conceptualizados desde un punto de vista sustantivo. En el evento que así suceda, veremos que se produce un particular efecto en sus relaciones con otros tipos normativos. Analicemos la cuestión.

\section{a) Las leyes interpretativas de la Constitución}

A pesar de que su regulación a nivel constitucional sólo aparece con el texto de la Carta de 1980, sus antecedentes se remontan a la Constitución de 1828, teniendo una particular importancia bajo la Constitución de 1833 y 1925. Así las cosas, esto permitió a la doctrina y la jurisprudencia formular un concepto sustantivo, siguiendo muy de cerca el concepto de interpretación auténtica que se había forjado a nivel legal, especialmente en el ámbito del Derecho civil ${ }^{6}$.

Es así como la jurisprudencia ha señalado que la ley interpretativa de la Constitución es aquella que tiene por objeto aclarar o determinar el sentido dudoso, oscuro o controvertido de un precepto constitucional ${ }^{7}$. Este es, por lo demás, el concepto que han

Ramón Areces, 1991, pp. 513-554. En Chile se puede consultar Varas Alfonso, P., "El nuevo concepto de ley en la Constitución de 1980", en Revista Chilena de Derecho de la Facultad de Derecho de la Pontificia Universidad Católica de Chile, vol. 11, Nos. 2-3, 1984, pp. 377-384, y Caldera Delgado, H., "La obsolescencia del concepto de ley del Código Civil y las nuevas relaciones entre la ley y el reglamento a consecuencia de la entrada en vigencia de la Constitución de 1980", en Revista de Derecho y Jurisprudencia y Gaceta de los Tribunales, N 2 , T. 82,1985 , pp. 25-31.

${ }^{5}$ Por tal razón, afirma que esta conversión obliga al Estado a dar respuesta a todo tipo de situaciones de alta complejidad y evolución social, por lo que "[...] difícilmente puede sostenerse que, en el cumplimiento de tal cometido, ha de actuar privado del instrumento de acción fundamental que representa la Ley”. Esto sería la causa de la crisis de sus notas de generalidad y estabilidad. Véase Parejo Alfonso, L. Derecho administrativo, Barcelona, Ariel, 2003, p. 249.

6 Véase Alessandri, A., Somarriva, M. y Vodanovic, A., Tratado de Derecho Civil. Parte preliminar y general, Santiago, Editorial Jurídica, 2005, pp. 193 y ss., y Claro Solar, Luis, Explicaciones de Derecho Civil y Comparado, T. I, Santiago, Editorial Jurídica de Chile, p. 70.

${ }^{7}$ Véase Sentencia del Tribunal Constitucional Rol No 12 , de 16 de julio de 1982, considerando $21^{\circ}$. 
seguido la doctrina nacional ${ }^{8}$ y la CENC en el texto del Anteproyecto en los siguientes términos: "Las leyes que interpreten los preceptos constitucionales no podrán vulnerar el sentido de sus disposiciones y requerirán de quórum calificado"9.

Teniendo estas leyes la función que se ha indicado, las materias que puede comprender o abarcar no reconocen una enumeración taxativa, aun cuando tampoco son ilimitadas. En efecto, el objeto de las leyes interpretativas es establecer el sentido y alcance de los preceptos contenidos en la Constitución. Así, todas y cada una de las normas contenidas en la Carta Fundamental pueden ser objeto de estas leyes, de forma tal que ninguno de estos preceptos puede estar exceptuado de dicha posibilidad.

Por su parte, el efecto de estas leyes es de una importancia notable, en la medida que se produce una suerte de integración plena entre la norma constitucional interpretada y la ley interpretativa, al punto que debe entenderse que dicha disposición siempre ha tenido el sentido y alcance que le fija esta ley, con toda la fuerza y vinculación que irradia una norma constitucional ${ }^{10}$. De esta forma, si bien la Constitución considera que estas normas son un tipo de ley, lo cierto es que en cuanto a sus efectos se produce una alteración de las formas en que se puede relacionar con otras leyes, en la medida que su contenido proyecta las consecuencias propias de una norma constitucional, esto es, supremacía o, derechamente, jerarquía.

No obstante lo anterior, actualmente cabe preguntarse por el sentido que tiene en el sistema de fuentes este tipo de leyes. La importancia capital que tuvieron bajo la Constitución de 1833 y de 1925 ha disminuido considerablemente bajo la vigencia de la actual Constitución. La explicación se puede encontrar en la relación estrecha que se produce entre los procedimientos de reforma a la Constitución y los previstos para la dictación de una Ley interpretativa. Así, en los casos en que los procedimientos de reforma a la Constitución sean más exigentes, cobra mayor relevancia la Ley interpretativa, pero, en caso contrario, la importancia relativa de la misma disminuye de forma considerable. Esto ocurrió bajo vigencia de la Constitución de 1833 y se ha visto durante la actual Constitución. La excepción la constituye, en alguna medida, la Carta de 1925, la que no consideró la existencia de leyes interpretativas teniendo presente que los procedimientos de reforma a la misma eran mucho más flexibles; sin embargo, la práctica legislativa llevó a la dictación de normas interpretativas de la Constitución bajo la forma de ley, muchas de las cuales constituían auténticas reformas encubiertas sujetas a un procedimiento menos estricto de aprobación. Esta fue una de las razones que explican el estricto control que ejerció la Corte Suprema respecto de estas leyes conociendo de diversos recursos de inaplicabilidad, siendo absolutamente clara en señalar que la ley

${ }^{8}$ Véase Cea Egaña, J. L., Teoría del Gobierno. Derecho Chileno y Comparado. Santiago, Ediciones Universidad Católica de Chile, 2000, pp. 118-119; Silva Bascuñán, A., Tratado de Derecho Constitucional, $2^{a}$ ed. T. VII, Santiago, Editorial Jurídica de Chile, 2000, p. 41; Vivanco A., Curso de Derecho Constitucional, T. I, Santiago, Ediciones Universidad Católica de Chile, 2007, p. 402.

${ }^{9}$ Artículo 69 inciso $2^{\circ}$ del Anteproyecto de la CENC.

${ }^{10}$ En este sentido Cea Egaña (n. 7), p. 119, señala que el contenido de esta ley "se entiende incorporado al Código Político interpretado”. En el mismo sentido se pronuncia Silva Bascuñán (n. 7), p. 54. 
sólo debía reiterar la voluntad ya existente, no pudiendo hacer una nueva declaración ni contener normas nuevas o diversas ${ }^{11}$.

La regulación expresa de estas leyes en la Carta Fundamental y diversas reformas posteriores han llevado a que lentamente hayan disminuido en importancia, al punto que sólo se han dictado una cantidad ínfima durante todo el período de vigencia de la actual Carta $^{12}$. Más aún, cabe preguntarse cuál sería su sentido actual si los procedimientos de elaboración y aprobación de estas leyes son casi idénticos a los previstos para una reforma constitucional, tal como lo demuestra el siguiente cuadro:

\begin{tabular}{|c|c|c|c|}
\hline & Leyes interpretativas & $\begin{array}{l}\text { Reforma constitucional } \\
\quad \text { (Regla general) }\end{array}$ & $\begin{array}{l}\text { Reforma constitucional } \\
\quad \text { (Regla especial) }\end{array}$ \\
\hline $\begin{array}{l}\text { Constitución } \\
\text { de } 1980\end{array}$ & $\begin{array}{l}3 / 5 \text { partes de los diputados } \\
\text { y senadores en ejercicio, más } \\
\text { control previo obligatorio de } \\
\text { constitucionalidad. } \\
\text { (artículos } 63 \text { y } 82 \mathrm{~N}^{\mathrm{o}} 1 \text { ) }\end{array}$ & $\begin{array}{l}\text { 3/5 partes de los diputados } \\
\text { y senadores en ejercicio, más } \\
\text { Congreso Pleno. } \\
\text { (artículos } 116 \text { y 117) }\end{array}$ & $\begin{array}{l}\text { - } 2 / 3 \text { partes de los diputados } \\
\text { y senadores en ejercicio, más } \\
\text { Congreso Pleno. } \\
\text { (inc. } 1^{\circ} \text { artículo } 118 \text { ) } \\
-2 / 3 \text { partes, más Congreso } \\
\text { Pleno, más ratificación en } \\
\text { el período parlamentario } \\
\text { siguiente. } \\
\text { (inc. } 2^{\circ} \text { artículo } 118 \text { ) }\end{array}$ \\
\hline $\begin{array}{c}\text { Reforma } \\
\text { Ley } \mathrm{N}^{\circ} 18.825 \\
\text { de } 1989\end{array}$ & $\begin{array}{l}\text { 3/5 partes de los diputados } \\
\text { y senadores en ejercicio, más } \\
\text { control previo obligatorio de } \\
\text { constitucionalidad. } \\
\text { (artículos } 66 \text { y } 93 \mathrm{~N}^{\circ} 1 \text { ) }\end{array}$ & $\begin{array}{l}\text { 3/5 partes de los senadores y } \\
\text { diputados en ejercicio, más } \\
\text { Congreso Pleno. } \\
\text { (inc. } 2^{\circ} \text { artículo } 116 \text { ) }\end{array}$ & $\begin{array}{l}2 / 3 \text { partes de los diputados } \\
\text { y senadores en ejercicio, más } \\
\text { Congreso Pleno, respecto de } \\
\text { los Capítulos I, III, VII, X, } \\
\text { XI o XIV. } \\
\text { (inc. } 2^{\circ} \text { artículo } 116 \text { ) }\end{array}$ \\
\hline $\begin{array}{c}\text { Reforma } \\
\text { Ley } \mathrm{N}^{\circ} 20.050 \text {, } \\
\text { de } 2005\end{array}$ & $\begin{array}{l}3 / 5 \text { partes de los diputados } \\
\text { y senadores en ejercicio, más } \\
\text { control previo obligatorio de } \\
\text { constitucionalidad. } \\
\text { (artículos } 66 \text { y } 93 \mathrm{~N}^{\circ} 1 \text { ) }\end{array}$ & $\begin{array}{l}3 / 5 \text { partes de los senadores y } \\
\text { diputados en ejercicio. } \\
\text { (inc. } 2^{\circ} \text { artículo } 127 \text { ) }\end{array}$ & $\begin{array}{l}\text { 2/3 partes de los diputados } \\
\text { y senadores en ejercicio, } \\
\text { respecto de los Capítulos I, } \\
\text { III, VII, X, XI o XIV. } \\
\text { (inc. } 2^{\circ} \text { artículo } 127 \text { ) }\end{array}$ \\
\hline
\end{tabular}

${ }^{11}$ Véanse Corte Suprema, Sentencia de 4 de octubre de 1974, RDJ, T. 71, sección 3ª p. 180; Sentencia de 11 de octubre de 1976, Revista Fallos del Mes, No 215, p. 231; Sentencia de 30 de agosto de 1976, Revista Fallos del Mes, N $\mathrm{N}^{\circ} 213$, p. 167; y Sentencia de $1^{\circ}$ de septiembre de 1980, RDJ, T. 77, sección $1^{\circ}$, p. 160.

12 Véanse la Ley $\mathrm{N}^{\circ} 18.152$, de 2 de agosto de 1982, que interpreta el artículo $19 \mathrm{~N}^{\circ} 24$ de la Constitución respecto del derecho de propiedad sobre la reajustabilidad de las pensiones; Ley $\mathrm{N}^{\mathrm{o}}$ 18.799, de 26 de mayo de 1989, que interpretó las disposiciones vigésima primera y vigésima novena transitorias de la Constitución a efectos de la primera elección parlamentaria realizada el mismo año; y Ley N ${ }^{\circ} 19.174$, de 12 de noviembre de 1992, que interpretó la disposición trigésima tercera transitoria, relativa a la fecha de las elecciones de los consejos regionales. 
Como bien se puede apreciar, en la medida que han disminuido los quórum y se han eliminado algunas formalidades para la reforma constitucional (Congreso Pleno), el procedimiento de aprobación de una Ley interpretativa coincide con el procedimiento común exigido para las reformas constitucionales. Más aún, las Leyes interpretativas tienen un requisito adicional: el control previo y obligatorio de constitucionalidad por parte del Tribunal Constitucional.

Así las cosas, cabe preguntarse por el sentido que tendrían actualmente estas leyes cuando se produce esta suerte de identidad casi plena con los procedimientos de reforma constitucional. En nuestra opinión, las únicas posibles respuestas serían dos: a) en el caso de interpretar los preceptos constitucionales contenidos en los Capítulos I, III, VII, X, XI o XIV de la Constitución, en donde el quórum de reforma es superior (2/3 partes de los diputados y senadores en ejercicio); y b) por el efecto retroactivo propio de las Leyes interpretativas, pues se debe entender que el sentido y alcance que se fija para estas normas opera desde la entrada en vigencia del precepto constitucional interpretado. Sin embargo, en este último punto la reforma constitucional también podría darle tales efectos, siempre que los mencione expresamente.

En resumen, el sometimiento de la reforma constitucional a procedimientos menos estrictos ha hecho que la importancia de las Leyes interpretativas haya disminuido considerablemente, al punto que sólo tiene sentido en casos bastante acotados. Por tal razón, la preocupación planteada por algunos autores en torno a un posible efecto de vaciamiento y desconstitucionalización de la Constitución por la Ley interpretativa parece esfumarse ante las exigencias formales que se prevén para su aprobación, las cuales casi la colocan al nivel de la reforma constitucional ${ }^{13}$.

\section{b) Las Leyes orgánicas constitucionales}

Respecto de las Leyes orgánicas constitucionales, nuestra doctrina se ha hecho eco de la discusión habida en derecho comparado, particularmente en España, pero esta se ha ido decantando en una etapa posterior a la entrada en vigencia de la Constitución de 1980 , al punto de que le ha dado a estas leyes una fisonomía propia que la distingue de los modelos que le han servicio de antecedente.

En un comienzo nuestro Tribunal Constitucional se movió entre un concepto procedimental y sustancial de Ley orgánica. En la sentencia de 26 de noviembre de 1981, Rol $N^{\circ} 4$, sostuvo que "[...] formalmente tales leyes se caracterizan por versar sobre determinadas materias que la Constitución ha señalado de un modo explícito dada la importancia que les atribuye; necesitarán para su aprobación, modificación o derogación de los tres quintos de los diputados y senadores en ejercicio; las materias reservadas a ellas no pueden ser objeto de delegación de facultades legislativas y deben ser sometidas antes de su promulgación al Tribunal Constitucional para su control de constitucionalidad”.

${ }^{13}$ Véase Zúñiga Urbina, F., "Constitución y ley interpretativa. Algunas notas sobre una paradoja y peligros relativos a este tipo de ley”, en Ius et Praxis, vol. 15, No 2, 2009, pp. 255-281. 
Acto seguido señala que dentro de las materias de Ley orgánica se debe comprender el "contenido imprescindible como sus elementos complementarios indispensables, esto es, aquellos elementos que, lógicamente, deben entenderse incorporados en el rango propio de esa determinada ley orgánica constitucional" ${ }^{14}$.

Al poco tiempo, el Tribunal comienza a diseñar un concepto sustantivo de la mano del Ministro Eugenio Valenzuela. En la sentencia de 22 de diciembre de 1981, Rol $\mathrm{N}^{\circ} 7$, señala que para determinar el contenido específico que deben tener las materias reservadas a las Leyes orgánicas constitucionales es necesario recurrir al espíritu del constituyente al incorporarlas a nuestro sistema jurídico, reflejado en su objetivo, en los preceptos que las consagran y en sus características esenciales. Así, llega a sostener que "su objetivo es desarrollar en un texto armónico y sistemático los preceptos constitucionales en aquellas materias que el constituyente ha reservado a dichas leyes. Según su filosofía matriz, puede decirse que esta nueva categoría de leyes está llamada a ocupar un lugar intermedio entre la Constitución y la ley común"15.

Hay tres ideas que debemos destacar y que son fundamentales sobre esta materia. En primer lugar, la identificación de las Leyes orgánicas con textos armónicos y sistemáticos, cuestión que deriva de la idea de organicidad que debe tener un cuerpo normativo. A su vez, y en segundo término, necesariamente esta noción de cuerpos normativos armónicos y sistemáticos obliga a extender el contenido que deben comprender estas leyes a dos materias: a) aquellas que del contexto de la norma constitucional y de una interpretación armónica de la misma permitan concluir que son materias de Ley orgánica constitucional, aun cuando no lo diga expresamente; y b) aquellas que constituyen un complemento indispensable, pues si ellas se omitieran no se lograría el objetivo del Constituyente al incorporar esta clase de leyes en nuestro sistema positivo, cual es desarrollar normas constitucionales sobre materias de la misma naturaleza en cuerpos legales autónomos, armónicos y sistemáticos ${ }^{16}$. Por último, la idea de que estos textos normativos tienen un lugar intermedio entre la Constitución y la ley común, dando la impresión de que estaríamos frente un tipo de ley de rango superior y de mayor jerarquía respecto de la ley ordinaria.

Ahora bien, lo cierto es que esta concepción sustancial de Ley orgánica comenzó a ser objeto de críticas por parte de la doctrina, especialmente en lo que dice relación con la extensión de las materias que pueden ser objeto de este tipo de leyes y, sobre todo, con la noción de "complemento indispensable"17. Por su parte, la idea de superioridad jerárquica o posición intermedia también ha recibido sus reparos por parte de los autores y no ha sido reiterada posteriormente por el Tribunal en sus sentencias.

${ }^{14}$ Considerando $4^{\circ}$.

${ }^{15}$ Considerando $8^{\circ}$. El destacado es nuestro.

16 Así se ha precisado en la sentencia de 29 de febrero de 1988 , Rol No 50 , considerando $2^{\circ}$.

17 Véanse Ríos Alvarez, L. "Las leyes orgánicas constitucionales", en Revista Chilena de Derecho, vol. 10, $\mathrm{N}^{\mathrm{o}}$ 1, enero-abril 1983, pp. 39-44; y Mohor S. y Varas P., "En torno a la Ley orgánica constitucional sobre sistema de inscripciones electorales y Servicio Electoral”, en Revista de Derecho, Universidad Católica de Valparaíso, X, 1986, pp. 258-261. 
La relación hecha demuestra cómo en sus primeras sentencias el Tribunal Constitucional trató de mantener el concepto unitario y sistemático de Ley orgánica, evitando que una interpretación extensiva de la misma diera lugar a la existencia de estas normas al margen de los textos que habían sido formalmente aprobados en tal calidad. Esto tuvo lugar, especialmente, respecto de las normas relativas a la organización y atribuciones del Poder Judicial, las cuales salpicaban en una importante cantidad de leyes comunes ${ }^{18}$. Así, sus esfuerzos se centraron en limitar el alcance de estas leyes a la estructura básica del Poder Judicial ${ }^{19}$, pero lentamente fue cediendo al punto de aceptar la existencia de Leyes orgánicas constitucionales al margen del Código Orgánico de Tribunales y en textos aislados ${ }^{20}$. Por su parte, esto ya se había presentado en materia minera, cuando el Tribunal Constitucional reconoció que el Código de Minería podría contener normas orgánicas constitucionales al margen de la Ley Orgánica Constitucional de Concesiones Mineras $^{21}$.

La descomposición definitiva de este concepto sustantivo se presentó bajo la tesis inversa, es decir, en los casos de Leyes orgánicas que contenían disposiciones de ley común. También en un comienzo el Tribunal trató de justificar esta situación bajo el concepto de "complemento indispensable", lo que le permitía extender el ámbito de las LOC más allá de los términos establecidos por la Constitución. Sin embargo, lentamente tuvo que reconocer que la idea de un texto único, sistemático y unitario debía ceder a un concepto de carácter procedimental. El primer caso se dio a propósito de la citada Ley Orgánica de Concesiones Mineras, cuando sostuvo que no puede pronunciarse sobre uno de los artículos debido a que, de acuerdo al texto expreso de la Constitución, la materia de que trata no es propia de Ley orgánica constitucional, sino del Código de Minería $^{22}$. Este criterio comienza a ser aplicado de forma constante por el Tribunal, siendo una práctica habitual que en sus resoluciones se contenga un listado de normas

\footnotetext{
${ }^{18}$ No se debe olvidar que la regulación de una determinada materia exige habitualmente la atribución de competencias a un órgano jurisdiccional llamado a pronunciarse sobre la materia. Así las cosas, prácticamente era imposible encontrar una ley que no contuviera disposiciones orgánicas constitucionales relativas a la organización y funcionamiento del Poder Judicial.

${ }^{19}$ Véase Sentencia de 26 de noviembre de 1981, Rol N 4, en donde sostiene que "[...] el concepto “organización y atribuciones de los tribunales” empleado en el artículo 74 de la Constitución se refiere a la estructura básica del Poder Judicial en cuanto ella no está reglada por la propia Carta Fundamental, pues dice relación con lo necesario "para la pronta y cumplida administración de justicia en todo el territorio de la República”. El propio constituyente se ha encargado de advertir que no todo lo relacionado con esta materia queda bajo el ámbito de la Ley orgánica constitucional, pues ha reservado a la competencia de la ley común, en su artículo $60, \mathrm{~N}^{\circ} 3$, los preceptos "que son objeto de codificación, sea civil, comercial, procesal, penal u otra”, y en el $\mathrm{N}^{\circ} 17$ del mismo precepto deja a la ley común señalar la ciudad en la cual deba funcionar la Corte Suprema" (considerando $6^{\circ}$ ). En el mismo sentido véase Sentencia de 22 de diciembre de 1981, Rol N 7 , considerando $5^{\circ}$. Sobre esta idea ha vuelto en la sentencia de 17 de marzo de 2009, Rol $\mathrm{N}^{\circ} 1145$, considerando $17^{\circ}$.

${ }^{20}$ Véase Sentencia Rol No 88, de 26 de diciembre de 1989 y, especialmente, Sentencia Rol No 115 , de 3 de diciembre de 1990 .

${ }^{21}$ Sentencia Rol No 17 , de 23 de agosto de 1983.

${ }^{22}$ Sentencia Rol No 10 , de 22 de diciembre de 1981.
} 
sobre las cuales no se pronunciará, en razón de que no regulan materias de Ley orgánica constitucional $^{23}$. La ruptura definitiva se produce cuando el Tribunal sostiene que para “[...] determinar si una modificación legal tiene el rango propio de una Ley orgánica constitucional -como se ha planteado en la especie-, hay que buscar la respuesta atendiendo al ámbito específico que el Constituyente ha reservado a este tipo de leyes, las que, por lo demás, son taxativas” 24 . Así las cosas, a priori, una ley que reforma el Código Orgánico de Tribunales o la Ley Orgánica de Municipalidades no será necesariamente una Ley orgánica constitucional ${ }^{25}$.

El segundo elemento que le daba sustantividad al concepto de Ley orgánica por parte del Tribunal Constitucional era el del "lugar intermedio" que tendrían estas leyes entre la Constitución y la ley común ${ }^{26}$. En buenas cuentas, el Tribunal estaba sosteniendo la idea de superlegalidad o jerarquía de estas normas sobre las leyes ordinarias, lo cual fue objeto de varias críticas por parte de la doctrina nacional, siendo en gran medida un reflejo de la tesis sustentada por la doctrina española. Tal como lo hemos señalado, el Tribunal Constitucional no mantuvo esta declaración en sus sentencias posteriores. Más aún, al momento de examinar este problema ha entendido que la cuestión está vinculada fundamentalmente a un problema de forma o de procedimiento, como se da cuenta en varias sentencias ${ }^{27}$. Así, el segundo elemento de sustantividad conceptual es abandonado.

Por lo tanto, la Ley orgánica constitucional no constituye una categoría sustancialmente diversa a la ley, en la medida que los elementos que la configuran no tienen por objeto alterar su naturaleza, sino establecer reglas de procedimiento más rigurosas para su elaboración. Esta cuestión será fundamental al momento de establecer y analizar los criterios que se utilizarán para resolver las relaciones y conflictos que se presentan entre las Leyes orgánicas y los otros tipos de leyes.

\section{c) Las Leyes de quórum calificado}

La Ley de quórum calificado (en adelante LQC) también es un tipo de ley que introdujo la Constitución de 1980, sin tener a la vista un modelo de derecho comparado. Por tal razón, bien se podría señalar que se trata de una categoría original de nuestro ordenamiento, aunque -como luego se verá- su consagración no responde a una decisión consciente o deliberada por parte de los redactores de la Carta Fundamental.

${ }^{23}$ Véase Sentencia Rol No 13 , de 24 de septiembre de 1982; No 14,14 de octubre de 1982; N 20 , de 6 de diciembre de 1984; $\mathrm{N}^{\circ} 24$, de 4 de diciembre de 1984, entre otras.

${ }^{24}$ Véase Sentencia Rol No 1.145 , de 17 de marzo de 2009, considerando $18^{\circ}$.

${ }^{25}$ Véase Sentencia Rol No 14, 14 de octubre de 1982; No 20, de 6 de diciembre de 1984; y No 1.145 , de 17 de marzo de 2009.

${ }^{26}$ Véase Sentencia Rol N ${ }^{\circ}$, de 22 de diciembre de 1981, considerando $8^{\circ}$.

${ }^{27}$ Véanse en materia minera las sentencias $\mathrm{Rol} \mathrm{N}^{\circ} 256$, de 19 de agosto de $1997 ; \mathrm{N}^{\circ} 473$, de 8 de mayo de 2007; $\mathrm{N}^{\circ} 517,8$ de mayo de 2007; $\mathrm{N}^{\circ} 535,8$ de mayo de 2007; $\mathrm{N}^{\circ} 588$, de 26 de julio de 2007; $\mathrm{N}^{\circ} 589$, de 21 de agosto de 2007; $\mathrm{N}^{\circ} 623$ de 10 de septiembre de 2007; y $\mathrm{N}^{\circ}$ 612, de 2 de octubre de 2007, entre otras. Recientemente se puede consultar la sentencia Rol No 1.145, de 17 de marzo de 2009. 
La CENC se hizo cargo del tema de la LQC a propósito del estudio de los quórum de aprobación de las leyes. En un comienzo sólo se consideraban dos tipos de leyes, aquellas llamadas leyes complementarias de la Constitución -posteriormente denominadas Leyes orgánicas constitucionales-y las leyes comunes ${ }^{28}$. En la sesión $\mathrm{N}^{\circ} 389$, del 27 de junio de 1978, la CENC se plantea el "problema de las leyes comunes que requieren quórum especiales en ambas Cámaras, pero que no son leyes orgánicas constitucionales”. En este caso la distinción entre unas y otras estaba vinculada al sentido que les estaba dando a las leyes orgánicas. Mientras éstas eran leyes complementarias de la Constitución contenidas en textos únicos y sistemáticos, las denominadas "leyes de quórum especial" se correspondían a casos concretos o particulares que, debiendo ser objeto de ley común, el Constituyente exigía un quórum más alto de aprobación. De esta forma se explica que en su propuesta la CENC asignara el mismo quórum de aprobación a las Leyes orgánicas y a las LQC (mayoría absoluta de los diputados y senadores en ejercicio), y que luego señale que "las leyes que interpreten los preceptos constitucionales [...] requerirán de quórum calificado”. En buenas cuentas, la expresión quórum calificado -que aparece por primera vez en esta propuesta- sólo se refería a un elemento formal que se debía respetar al momento de aprobar determinados cuerpos legales ${ }^{29}$. Por su parte, el Consejo de Estado mantuvo el texto propuesto con una leve modificación ${ }^{30}$.

Fue la Junta de Gobierno la que produjo la cesura o separación entre las Leyes orgánicas y las Leyes interpretativas, por una parte, respecto de las LQC, por otra, en la propuesta aprobada posteriormente y que entró en vigencia el 11 de marzo de 1981. Más adelante, con la reforma constitucional de la Ley $\mathrm{N}^{\circ} 18.825$ de 1989, se hace la separación tripartita en el artículo 63 (actual artículo 66) entre Ley interpretativa de la Constitución, Ley orgánica constitucional y LQC en relación a su quórum de aprobación.

Nuevamente se comprueba que respecto de la LQC no es posible sustentar un concepto sustantivo, en la medida que éste sólo se construye sobre la base de una ley común sometida a un procedimiento más agravado de aprobación.

${ }^{28}$ Véanse Sesión $N^{\circ} 9$ del 23 de octubre de 1973; No 11 del 30 de octubre de 1973; Nº 18 de 22 de noviembre de 1973; y N 22 del 12 de marzo de 1974.

${ }^{29}$ El Artículo 69 del Anteproyecto de la CENC establecía lo siguiente:

Artículo 69. Las leyes a las cuales la Constitución confiere el carácter de leyes orgánicas constitucionales y aquellas respecto de las cuales exija un quórum calificado, necesitarán para su aprobación, modificación o derogación, de la mayoría absoluta de los diputados o senadores en ejercicio.

Las leyes que interpreten los preceptos constitucionales no podrán vulnerar el sentido de sus disposiciones y requerirán de quórum calificado.

${ }^{30}$ Véase Sesión N $\mathrm{N}^{\mathrm{0}}$ 8, del 4 de septiembre de 1979, del Consejo de Estado. El texto aprobado queda en los siguientes términos:

Artículo 63. Las leyes a las cuales la Constitución confiere el carácter de leyes orgánicas constitucionales y aquellas respecto de las cuales exija un quórum calificado, necesitarán para su aprobación, modificación o derogación, de la mayoría absoluta de los diputados o senadores en ejercicio.

Las leyes que interpreten los preceptos constitucionales requerirán de quórum calificado. 


\section{d) Las leyes comunes, simples $u$ ordinarias}

La ley común, simple y ordinaria se ha definido en base a dos elementos básicos: a) le corresponde regular todas aquellas materias de ley que no son objeto de Ley orgánica constitucional de LQC, de acuerdo a los términos del artículo 63 de la Constitución; y b) se encuentra sometida a un procedimiento común que regula la iniciativa, tramitación y aprobación de las mismas, de acuerdo a los términos establecidos en la Constitución y su legislación complementaria. Así las cosas, en un primer acercamiento este tipo de leyes presentan un carácter formal o procedimental. Sin embargo, de los antecedentes y preceptos de la Constitución es posible encontrar dos elementos estrechamente asociados y que le dan una sustantividad particular a las leyes. En primer término, se asigna a la ley una función reguladora sobre la base de preceptos generales y obligatorios que estatuyan las bases esenciales del ordenamiento jurídico, de manera de evitar que regule aspectos contingente o de detalle, propios de la potestad reglamentaria o de actos administrativos singulares, salvo en los casos expresamente exceptuados (artículo $63 \mathrm{~N}^{\circ} 20$ ). En segundo lugar, la ley se transforma en una norma de clausura de las materias de ley, estableciendo el límite que ha de tener respecto de la regulación reglamentaria.

La existencia de un concepto sustantivo de ley era una aspiración que se venía gestando en Chile desde la vigencia de la Constitución de 1925, cuestión que queda claramente expresada en la discusión de la Ley de Reforma Constitucional $\mathrm{N}^{\circ} 17.284$ de $1970^{31}$, y que luego se retoma al interior de la $\mathrm{CENC}^{32}$, cuya idea fundamental fue la de propender "[...] a que la ley sea una norma de carácter general dirigida al bien común, es decir, que se limite a contener sólo las bases esenciales del ordenamiento sobre el cual estatuye, sin penetrar en el campo de la potestad reglamentaria, que es propio del Poder Ejecutivo" 33 . Por su parte, la doctrina tempranamente dio cuenta también de este cambio sustantivo ${ }^{34}$, con la introducción de lo que se ha denominado el concepto de Ley material ${ }^{35}$.

31 Véase el Informe de la Comisión de Constitución, Legislación, Justicia y Reglamento del Senado relativo a esta reforma de fecha $1^{\circ}$ de septiembre de 1969, Boletín $\mathrm{N}^{\circ} 24.120$. Los antecedentes de la tramitación de esta ley se pueden consultar en Andrade (n. 2), pp. 472-494.

${ }^{32}$ Véanse Sesiones $N^{\circ} 9$ del 23 de octubre de 1973; N 11 del 30 de octubre de 1973; N 18 de 22 de noviembre de 1973; $\mathrm{N}^{\mathrm{o}} 22$ de 12 de marzo de 1974; $\mathrm{N}^{\circ} 26$ de 26 de marzo de $1974 ;$ y $\mathrm{N}^{\circ} 358$ de 25 de abril de 1978.

33 Véase Comisión de Estudios de la Nueva Constitución, "Proposiciones e ideas precisas", en Revista Chilena de Derecho, vol. 8, N ${ }^{\text {os. }} 1-6$, enero-diciembre, 1981, pp. 144-317, en particular se deben consultar pp. 263-264.

${ }^{34}$ Véase Bulnes Aldunate, Luz, "Leyes de base y potestad reglamentaria en la Constitución de 1980", en Revista de Derecho, Universidad Católica de Valparaíso, VI, 1982, pp. 133-153; Varas Alfonso (n. 4), pp. 377-384; y Caldera (n. 4), pp. 25-31.

${ }^{35}$ Nuestra doctrina ha utilizado el binomio Ley material y Ley formal, en cuanto la primera de éstas se caracterizaría por su regulación general y abstracta, a diferencia de la segunda. Véase Cea Egaña, J. L., "Dominio legal y reglamentario en la Constitución de 1980", en Revista Chilena de Derecho, vol. 11, Nos. 2-3, 1984, pp. 419, y Zúñiga Urbina, F., "Concepto de ley y tipos de ley. Notas acerca de jerarquía y competencia”, en Revista de Derecho, Universidad Católica de Valparaíso, XVIII, 1997, pp. 259-260. En todo caso se 
En otro trabajo hemos también dado cuenta de este punto, al sostener que el artículo $66 \mathrm{~N}^{\circ} 20$ de la Constitución no está señalando una materia que debe ser objeto de dominio legal, sino que está imponiendo a la ley la función/deber de regular de forma general y obligatoria las bases esenciales de un ordenamiento jurídico, dejando los aspectos complementarios o de detalle a la regulación reglamentaria ${ }^{36}$.

Por su parte, el Tribunal Constitucional también se ha manifestado en el mismo sentido, al señalar que al legislador le corresponde normar, con amplitud y profundidad, todo cuanto la certeza o seguridad jurídica exige en relación con el establecimiento y configuración de las obligaciones que se imponen, respetando los criterios de generalidad, abstracción, igualdad, carácter innovador y cualidad básica que singularizan a la ley en el sistema jurídico ${ }^{37}$.

Ahora bien, en este punto es importante destacar que estas características o cualidades que tradicionalmente se asignan a la ley simple u ordinaria, es una exigencia a todo tipo de ley, ya sea orgánica constitucional o de quórum calificado, en la medida que ninguna de ellas tiene una sustantividad que permita desgajarlas del tronco común al cual pertenecen. En ambos casos nos encontramos simplemente ante procedimientos, los que no separan ni eximen de la función que el Constituyente les ha asignado en el sistema de fuentes del derecho, con las excepciones o salvedades expresamente previstas. Así, por ejemplo, si la Ley orgánica debe tender a una regulación armónica o sistemática no es por un supuesto de carácter intrínseco que ésta tenga, sino porque se trata de una manifestación de la potestad legislativa que debe ejercerse conforme a los márgenes previstos por la Carta Fundamental.

\section{LAS RELACIONES ENTRE LOS DIVERSOS TIPOS LEGALES}

Una vez analizados los distintos tipos legales en el derecho chileno, nos corresponde entrar en uno de los temas capitales que debe afrontar todo operador jurídico, ante la posibilidad de encontrarse con disposiciones que sean contradictorias, cuestión que tradicionalmente se ha estudiado bajo el rótulo de las antinomias jurídicas.

No se trata en este caso de volver a repasar los criterios tradicionales sobre la materia, sino que de encontrar o hacer algunos matices frente a un ordenamiento jurídico que se nos aparece como un conjunto plural y complejo de normas. Así las cosas, el objetivo final es tratar de establecer criterios de solución frente a una diversidad de tipos legales que pueden entrar en conflicto al momento regular determinadas materias.

ha de tener presente que el origen de esta distinción proviene de la dogmática alemana del siglo XIX (Paul Laband y George Jellinek) y estaba vinculada a las normas que contienen proposiciones jurídicas (Rechtssatz), en la medida que su objeto es incidir en la esfera jurídica de los particulares (Ley material), frente a aquellas vinculadas al funcionamiento interno del Estado (Ley formal).

36 Véase Cordero (n. 1), pp. 11-49.

37 Véase Sentencia Rol No 370, de 9 de abril de 2003, considerando $34^{\circ}$. 
Así, por ejemplo, ¿cómo se resuelve la posible contradicción entre una Ley orgánica, una LQC y una ley común? ¿Qué sucede en el caso de que una ley común regule materias de Ley orgánica o de LQC? ¿Cómo se resuelve el problema a la inversa, es decir, cuando la Ley orgánica regula materias de LQC o de ley ordinaria? ¿Pueden existir leyes ilegales? Estos son algunos de los problemas que plantea nuestro ordenamiento jurídico a partir de la diversidad de tipos legales, y que demanda un criterio de solución que responda a la naturaleza y sentido que tienen este tipo de normas en nuestro ordenamiento.

Para este efecto, analizaremos los criterios que ha seguido nuestra doctrina sobre la materia (3.1.), para luego hacer una propuesta de solución a partir de la naturaleza de los tipos legales, ya sea introduciendo un nuevo criterio de solución de estos conflictos (3.2) o replanteando la función que cumplen actualmente algunos criterios tradicionales (3.3).

\subsection{Una discusión clásica: jerarquía v/s competencia}

La doctrina nacional se ha preocupado del tema centrándose fundamentalmente en las Leyes orgánicas constitucionales, aunque el problema es una cuestión común a las LQC. Ahora bien, el problema básico ha sido tratar de establecer la relación que se produce entre una Ley orgánica y una ley común, pues esto permitirá establecer el criterio de solución frente a una eventual antinomia.

Veamos el problema a partir de un ejemplo. El artículo $7^{\circ}$ de la Ley Orgánica Constitucional N $\mathrm{N}^{\mathrm{0}}$ 18.097, de Concesiones Mineras, publicada en el Diario Oficial el 21 de enero de 1982, establece que "[...] sólo el dueño del suelo podrá permitir catar y cavar en casas y sus dependencias o en terrenos que contenga arbolados o viñedos”. Por su parte, el Código de Minería, aprobado como ley común u ordinaria y publicado el 14 de octubre de 1983, dispone en el inciso final de su artículo 15 que "[...] tratándose de casas y sus dependencias o de terrenos plantados de vides y árboles frutales, sólo el dueño podrá otorgar el permiso". Como bien se puede apreciar, existe una clara antinomia entre lo que dispone una y otra norma al referirse a "arbolados" y a "árboles frutales". El tema no deja de ser relevante, pues las facultades del dueño varían sustancialmente en uno y otro caso, por ejemplo, si éste destina un predio a la explotación forestal. ¿Cómo resolvemos este conflicto de normas? ¿La Ley Orgánica Constitucional de Concesiones Mineras tiene mayor jerarquía que el Código de Minería?

El tema en la CENC no fue objeto de debate o discusión. Sin embargo, hay antecedentes claros en que la opinión general de sus integrantes era considerar a las Leyes orgánicas dotadas de una jerarquía superior y con un carácter intermedio entre la Constitución y la ley común ${ }^{38}$. Es por tal razón que el proyecto exigió quórum especial

38 Entre estos antecedentes se encuentran las intervenciones de Alejandro Silva Bascuñán y Sergio Díez en la Sesión No 9 del 23 de octubre de 1973. El señor Silva Bascuñán sostuvo que “[...] constituiría un progreso distinguir entre la legislación común y una jerarquía superior de normas que incluya las leyes complementarias en la Carta Fundamental o los preceptos que incidan en las materias trascendentales que el constituyente señale”. Por su parte, Sergio Díez señaló que “[...] a su juicio la nueva Constitución Política 
para su modificación, ya que debían "gozar de una mayor estabilidad y no deben quedar sujetas al capricho de mayorías ocasionales”. A su vez, y tal como lo hemos señalado, el Tribunal Constitucional también siguió esta tesis en una de sus primeras sentencias, aunque posteriormente cambió de posición ${ }^{39}$.

Sobre esta materia nuestra doctrina ha reflejado la discusión que se ha planteado en el derecho español, que bajo la Constitución de 1978 incorporó la figura de las Leyes orgánicas constitucionales tomándolas de la Constitución francesa de $1958^{40}$. Una parte de la doctrina ha entendido que la relación que se produce entre las Leyes orgánicas y la ley común se base en el principio de jerarquía normativa, considerando que se trata de normas complementarias de la Constitución, razón por la cual gozan de una suerte de "superlegalidad" expresada en un procedimiento de elaboración más estricto que el exigido para las leyes comunes u ordinarias ${ }^{41}$. Sin embargo, esta posición ha sido la excepción, pues al poco tiempo de la entrada en vigencia de la Carta de 1980 la mayoría de la doctrina se inclinó por el principio de competencia como el criterio que permitía explicar mejor la forma en que se articula la relación entre estos diversos tipos de leyes. Esta postura parte de la base de que las Leyes orgánicas constitucionales son manifestación de la potestad legislativa, no teniendo diferencias sustantivas respecto

debe contener las normas básicas en que se debe sustentar nuestro régimen institucional, dejando entregada a la ley complementaria -de carácter intermedio entre la Carta Fundamental y la ley ordinaria- el desarrollo de las materias que harán posible la aplicación de las disposiciones propiamente constitucionales [...]”. A su vez, en la Sesión $N^{\circ} 18$ de 22 de noviembre de 1973 se analizó el documento denominado "Metas u objetivos fundamentales para la nueva Constitución Política de la República”, en el cual señala que el proyecto: “c) Considerará dos categorías de leyes: las complementarias de la Constitución o básicas, como por ejemplo, la ley de Elecciones, el Estatuto de los Medios de Comunicación Social, las relativas al Régimen Interior, etcétera, y las ordinarias. Obviamente las primeras, que están llamadas a complementar la Carta Fundamental y a hacer posible la aplicación de sus disposiciones, deben gozar de una mayor estabilidad y no deben quedar sujetas al capricho de mayorías ocasionales. En razón pues, de la naturaleza y jerarquía de este tipo de leyes, el proyecto exigirá quórum especiales para su modificación”.

${ }^{39}$ Nos referimos a la Sentencia Rol No 7, de 22 de diciembre de 1981, en donde señala que el objetivo de las LOC es "[...] desarrollar en un texto armónico y sistemático los preceptos constitucionales en aquellas materias que el constituyente ha reservado a dichas leyes. Según su filosofía matriz, puede decirse que esta nueva categoría de leyes está llamada a ocupar un lugar intermedio entre la Constitución y la ley común" (considerando $8^{\circ}$ ). Sin embargo, en Sentencia Rol N ${ }^{\circ} 260$, de 13 de octubre de 1997, señala que el problema de las LOC es de competencia y no de jerarquía (considerando $25^{\circ}$ ).

${ }^{40}$ Para una completa relación de esta discusión en el Derecho español, véase Bastida, F., "La naturaleza jurídica de las leyes orgánicas. Comentario bibliográfico”, en Revista Española de Derecho Constitucional, N N $^{\circ}$, 1981, pp. 285-311. La explicación en base al criterio de jerarquía es compartida por Carretero Pérez, Díez Picazo, Garrido Falla, Lucas Verdú, Sánchez Agesta y Sosa Wagner, entre otros. Por su parte, el criterio de competencia es sostenido por Aragón Reyes, Tomás R. Fernández, González Montes, García de Enterría, Linde Paniagua, Martín Oviedo, Rubio Llorente, Santamaría Pastor y Villar Palasí, entre otros.

${ }^{41}$ Véase, Pantoja Bauzá, R., Bases generales de la Administración del Estado, Santiago, Ediar Cono-Sur, 1987, pp. 12-13 y 19-20; Bertelsen Repetto, R., "Informe en Derecho”, en Revista Chilena de Derecho, vol. 19, $\mathrm{N}^{\circ}$ 3, 1992, pp. 549-573; y Ríos Alvarez (n. 17), p. 41. Por su parte, Enrique Silva Cimma adscribió en un primer momento a esta posición en la $4^{\mathrm{a}}$ edición de su obra, Derecho administrativo chileno y comparado. Introducción y fuentes, Santiago, Editorial Jurídica de Chile, 1996, p. 106, aunque cambió de parecer en la $5^{\text {a }}$ edición publicada en el año 2009, pp. 124-125. 
de los demás tipos de leyes, de forma que no es posible explicar su relación en base a la subordinación o jerarquía. En caso contrario, se daría el posible contrasentido de que el ordenamiento jurídico previera no sólo leyes inconstitucionales, sino también leyes “ilegales”. En segundo término, y recurriendo a los elementos que aporta la teoría general del derecho, es posible que dentro de un sistema de normas se consideren un conjunto de subsistemas normativos debidamente delimitados, de forma que las normas que lo integran no pueden ser objeto de modificación o derogación por parte de normas de otro subsistema. Según la doctrina tradicional, esto permite explicar las relaciones que se producen entre la ley y los denominados reglamentos autónomos, en donde no es posible sostener una relación de subordinación para resolver las posibles interferencias que puedan producirse de un subsistema hacia el otro. En este caso se debe recurrir necesariamente al principio de competencia normativa. Así también ocurriría respecto de los diversos tipos de leyes. En este caso, existiría un campo material reservado por la Constitución a las Leyes orgánicas, el cual no puede invadir ni intervenir una LQC o un ley común ${ }^{42}$.

A su vez, el Tribunal Constitucional tiende a seguir esta segunda línea en una de sus sentencias, al señalar que "[...] si bien es efectivo que el constituyente ha entregado diversas materias a la regulación de la ley orgánica constitucional, ello no implica que estas leyes tengan una jerarquía superior a las otras leyes y mucho menos que puedan asimilarse a la Ley Fundamental. Del estudio de este instituto resulta que las leyes orgánicas constitucionales en Chile no pueden estimarse como preceptos constitucionales y sólo son normas complementarias de la Ley Fundamental [...]. Si se ha sostenido que las leyes orgánicas constitucionales tienen una jerarquía intermedia entre la Constitución y la ley (sesiones $N^{\text {os. }} 344,353$ y 358, de la Comisión de Estudios de la Nueva Constitución y Rol No 7, de 22 de diciembre de 1981, del Tribunal Constitucional) ello es sólo porque la propia Constitución les ha exigido mayores requisitos de forma, lo que en doctrina se denomina una superlegalidad de forma, pero no porque se haya querido privar a la ley orgánica de su jerarquía normativa de ley frente a la ley superior que es la Constitución. De aquí que el problema respecto de los distintos tipos de leyes sea de competencia y no de jerarquía" 43.

A pesar del consenso que parece existir en la doctrina y la jurisprudencia sobre esta materia, lo cierto es que el principio de competencia no satisface plenamente el problema que se ha planteado, tanto desde una perspectiva dogmática como en la forma que opera al momento de articular la relación entre las diversas leyes.

42 Véase Bulnes Aldunate, L., "La ley orgánica constitucional”, en Revista Chilena de Derecho, vol. 11, $\mathrm{N}^{\text {os. }} 2-3,1984$, p. 237; Caldera Delgado, H., "Ley orgánica constitucional y potestad reglamentaria", en Revista Chilena de Derecho, vol. 11, Nos. 2-3, 1984, pp. 455-459; del mismo autor, Las leyes orgánicas constitucionales, Santiago, Editorial Jurídica de Chile, 1985, p. 256; Zúñiga, (n. 35), p. 268; Bascuñán Rodríguez, A., "El principio de la distribución de competencias como criterio de solución de conflictos de normas jurídicas", en Revista Chilena de Derecho, Número especial, 1998, pp. 33-44; y Henríquez Viñas, M., Las fuentes formales del derecho, Santiago, LegalPublishing, 2009, pp. 68-69.

${ }^{4}$ Véase Sentencia Rol No 260 , de 13 de octubre de 1997 , considerandos $24^{\circ}$ y $25^{\circ}$. 
Desde una perspectiva dogmática, la competencia aparece asociada a las atribuciones que entrega el ordenamiento jurídico a diversos órganos públicos, de modo de establecer de forma positiva el marco de actuación de los mismos y, desde una perspectiva negativa, evitar que ésta pueda ser interferida por otros órganos. En definitiva, aparecen estrechamente asociados los conceptos de órgano, titular y competencia.

Ahora bien, si aplicamos este criterio a los diversos tipos legales comienza a operar una curiosa subjetivización que deforma estos tipos normativos, de manera de entenderlos como titulares de competencias o, en su caso, entidades afectadas por la intervención de otros sujetos en la órbita de sus competencias. Así, se comienza a hablar de un legislador orgánico constitucional, el legislador de quórum calificado y el legislador ordinario, como tres sujetos que tienen sus competencias acotadas y que están interdictos de intervenir en las competencias de los otros. Si bien la imagen que se proyecta entrega una perspectiva gráfica que hace más clara y atrayente la explicación, lo cierto es que desde una perspectiva dogmática ésta carece de todo sustento. Por su parte, la existencia de órganos competentes que participan del proceso legislativo es bastante acotada (Cámaras parlamentarias, Presidente de la República y el Tribunal Constitucional), y no se ve que se produzca una mutación en ellos que permita configurar esta suerte de pluralidad de legisladores. Dicho en otros términos, los parlamentarios son investidos en su cargo para ejercer las competencias que la Constitución y las leyes les han asignado. Al momento de aprobar una Ley orgánica o una LQC no tienen que asumir una nueva investidura ni mutar la anterior para transformarse en un legislador orgánico constitucional o de quórum calificado.

Al parecer, la figura ideal del legislador a la cual normalmente se recurre para dar cuenta de sus buenas o malas obras, omisiones o pecados, se ha extremado a tal punto que ha llevado a crear varios legisladores, sin reparar que se trata de una entelequia que carece de toda existencia real.

Por último, para cerrar este primer punto, no se entiende cómo se puede resolver un conflicto de normas en base al principio de la competencia, si el autor de dichas normas es la misma autoridad u órgano. En buenas cuentas, existiría un órgano titular de determinadas potestades normativas el que, al momento de ejercerlas, da lugar a una superposición o conflicto entre las mismas. Expuestas así las cosas, de inmediato uno puede preguntarse si podría constituir un conflicto de competencias el hecho de que las normas en conflicto reconozcan a un mismo autor. Al parecer, los conflictos que se resuelven en base al principio de competencia suponen, a lo menos, la existencia de más de un órgano o sujeto cuyos productos normativos entran en conflicto, cosa que no sucede con los tipos de leyes que estableció la Constitución de 1980, pues el autor es siempre uno.

En segundo lugar, el principio de la competencia tampoco nos entrega una respuesta adecuada a la forma en que se deben articular las relaciones entre los diversos tipos de leyes. Si bien este principio entrega una solución a los casos en que las leyes comunes contravienen lo dispuesto en una Ley orgánica, planteada la cuestión de forma inversa la solución puede llevar a un verdadero absurdo. En efecto, en el evento de que una Ley Orgánica Constitucional regulara materias de ley común, habría también una 
vulneración de la competencia que el Constituyente le habría entregado a este tipo de normas y, por tanto, un problema de constitucionalidad de la Ley orgánica. Así, por ejemplo, la Constitución establece en su artículo $8^{\circ}$ que la reserva o secreto de los actos o resoluciones de los órganos del Estado sólo se puede establecer en virtud de una LQC; sin embargo, hay varios casos en los cuales la reserva se encuentra establecida en Leyes orgánicas constitucionales ${ }^{44}$. En este supuesto, ¿es posible sostener que la Ley orgánica es inconstitucional por invadir la competencia de una LQC? Si se siguiera de forma estricta el principio de competencia, la respuesta debiese ser afirmativa, a pesar de que lleva a un absurdo evidente, pues el procedimiento de aprobación de una Ley orgánica constitucional es mucho más riguroso que el exigido para una LQC, tanto en su quórum como en su tramitación (control previo obligatorio de constitucionalidad).

Lo anterior obliga a revisar esta postura y a tratar de establecer un criterio que nos permita entregar una solución más adecuada para la resolución de estos conflictos de leyes.

\subsection{Una visión tridimensional: el procedimiento}

Hace poco más de 20 años, Santamaría Pastor explicaba las relaciones de las normas recurriendo de forma metafórica a las cuatro dimensiones de la geometría de Einstein, lo que le llevaba a hablar de la "estructura cuadridimensional del sistema normativo". En este caso nos encontrábamos con una dimensión vertical, asentada en el principio de jerarquía; una dimensión horizontal, construida sobre el principio de competencia; una dimensión de profundidad, expresada en el principio de procedimiento; y en una dimensión temporal, construida sobre la base del principio de sucesión cronológica o de posterioridad $^{45}$.

El tema del conflicto entre los diversos tipos de leyes se ha analizado tradicionalmente en una doble dimensión: jerarquía y competencia, siendo ambos principios objeto de críticas realmente insalvables para explicar la forma en que se articulan. Ahora bien, la inclusión de un nuevo principio para enfrentar este problema nos permite contar con una nueva perspectiva. Es una suerte de salto que va desde una visión centrada sólo en la superficie y que nos lleva a descubrir que nuestro objeto de estudio tiene un volumen del cual ha sido dotado a través de las reglas de procedimiento en la elaboración de las normas.

En este caso, el ordenamiento jurídico atribuye potestad normativa a un sujeto u órgano, pero diversifica los tipos de normas que puede dictar estableciendo un procedimiento diverso conforme a la materia que se va a regular. Si analizamos esto desde la perspectiva de la Constitución, lo que hace la Carta Fundamental es atribuir al poder legislativo una potestad normativa que se expresará a través de leyes, posteriormente

${ }^{44}$ Así, por ejemplo, el artículo 81 del Código Orgánico de Tribunales, el cual señala que las Cortes de Apelaciones celebrarán sus acuerdos privadamente, o el artículo 276 del mismo Código, el cual dispone que los procesos de calificaciones serán reservados.

45 Santamaría (n. 4), p. 314. 
determina cuáles son las materias que se regularán por este tipo de normas, luego separa estas materias considerando el tipo de ley que las va a regular y, por último, establece un procedimiento de elaboración y aprobación diverso para cada uno de éstos.

Cabe señalar que esta separación que se hace de materia-ley supone una decisión político-institucional, en cuya virtud hay una evidente valoración de la materia regulada y se determina un procedimiento de elaboración conforme a dicha valoración. Esto se expresa en la existencia de distintos tipos de leyes que regulan diversas materias, conforme a procedimientos también diferenciados.

Existe acuerdo en la doctrina nacional y en la jurisprudencia del Tribunal Constitucional en sostener que no hay una relación de supraordenación y, a su vez, de subordinación entre los diversos tipos legales. En definitiva, las Leyes orgánicas, las LQC y las leyes comunes pertenecen una sola categoría: todas son leyes.

En este punto debemos retomar lo dicho en la primera parte de este trabajo. Tal como hemos tenido ocasión de demostrar, no existe un concepto sustantivo de Ley orgánica constitucional y, menos aún, de LQC. Si bien la CENC y, en una primera etapa, el Tribunal Constitucional sostuvieron la idea de la sustantividad de las Leyes orgánicas como textos armónicos y sistemáticos que, por complementar los preceptos constitucionales, ocupaban una posición intermedia entre la Constitución y la ley común, lo cierto es que la jurisprudencia de dicho Tribunal, apoyada por la doctrina, ha abandonado dicho camino y se ha centrado en un concepto de carácter formal de Ley orgánica. Por su parte, las LQC fueron consideradas al interior de la CENC con un tipo ley común sujeta a un quórum más alto de aprobación.

Así las cosas, el elemento fundamental que permite definir a estos tipos de leyes son sus características formales. Dicho en otros términos, estas leyes no son sino procedimiento o forma que exige nuestra Constitución para la elaboración y aprobación de determinadas materias de reserva legal. En el evento de que no se respeten dichas condiciones externas, no es posible desde una perspectiva constitucional que una determinada materia pueda ser objeto de regulación legal. En definitiva, los tipos legales no son sino procedimientos de aprobación de la ley. Con toda razón, Nogueira Alcalá y Cumplido Cereceda sostienen, en la misma línea, que la Constitución ha "[...] introducido en nuestro ordenamiento jurídico, en la ordenación de las fuentes, el criterio de especialidad procedimental, dando lugar a una complementación del criterio jerárquico por el de reserva de materia" 46 .

Por su parte, la adopción de este principio nos ayuda a resolver el caso de tipos particularísimos de leyes, como ocurre con la Ley de Presupuestos y otras incorporadas con posterioridad a 1990 a la Carta Fundamental y que están sometidas a un quórum especial de aprobación. Esto ocurre con caso de las leyes que contienen indultos generales y amnistías de delitos terroristas, las que requieren para su aprobación de las dos terceras partes de los diputados y senadores en ejercicio, siendo que la regla general es el

${ }^{46}$ Nogueira Alcalá, H. y Cumplido Cereceda, F., Instituciones políticas y Teoría Constitucional, T. II, Talca, Editorial Universidad de Talca, 2001, p. 274. 
quórum calificado (artículo $63 \mathrm{~N}^{\mathrm{0}} 16$ de la Constitución) ${ }^{47}$. A su vez, las modificaciones a la LOC sobre Votaciones Populares y Escrutinios que digan relación con el número de senadores, las circunscripciones existentes y el sistema electoral vigente requerirán del voto conforme de las tres quintas partes de los diputados y senadores en ejercicio (Disposición decimotercera transitoria) ${ }^{48}$. Respecto de este último caso, la doctrina ha dado cuenta de las dificultades que plantea esta reforma, al punto de sostener que habría una auténtica distorsión del concepto de $\operatorname{LOC}^{49}$ o, en su caso, hará variar su concepto y podría importar a futuro "graves problemas interpretativos" 50.

Ahora bien, todos los casos mencionados no se pueden reconducir estrictamente a los tipos tradicionales de leyes, salvo que se sostuviera que en cada una de ellas existirían casos sometidos a un procedimiento especial o quórum más altos. ¿Podría afirmarse que la Ley de Presupuestos es una ley común sometida a un procedimiento especial? o ¿la ley que otorga indultos generales o amnistías por delitos terroristas es una ley de quórum calificado, pero con un quórum especial o más alto? Lo mismo se podría plantear respecto de los aspectos de la LOC de Votaciones Populares y Escrutinios que exigen un quórum superior al requerido por el artículo 63 de la Constitución. ¿Sigue siendo una LOC, pero con un quórum especial?

Si se analizan con detenimiento estos casos, lo cierto es que las mayores dificultades se plantean a nivel teórico más que en el ámbito práctico, pues una de las primeras tareas que realizan las Cámaras parlamentarias al momento de iniciar el proceso legislativo es determinar la materia que se regula y el procedimiento a seguir, sin hacer mayores disquisiciones respecto de la naturaleza de las leyes que están aprobando. A su vez, cuando estos temas llegan al Tribunal Constitucional, las partes lo han planteado como una eventual inconstitucionalidad de forma y así lo ha entendido también el Tribunal ${ }^{51}$.

Si tratamos de explicar el problema desde una perspectiva dogmática es evidente que los principios de jerarquía y competencia son insuficientes para dar respuesta a estos casos. Así, la formulación del principio de procedimiento como criterio para resolver estos eventuales conflictos aparece como la solución más adecuada, tanto desde una perspectiva teórico-dogmática como a nivel de los operadores jurídicos.

El efecto del principio del procedimiento como criterio para resolver estos conflictos es el propio de una compartimentación de materia, por tal razón -y como bien lo señala Santamaría Pastor- ofrece cierta semejanza con el principio de competencia, mas no es idéntico ${ }^{52}$. Desde un punto de vista positivo, este principio se traduce en que determinadas materias sólo pueden ser reguladas siguiendo el procedimiento previsto al efecto, ya sea de Ley orgánica o de quórum calificado. A su vez, y desde una perspectiva negativa, no

\footnotetext{
${ }^{47}$ Esta norma fue introducida por la Ley $\mathrm{N}^{\circ} 19.055$, de $1^{\circ}$ de abril de 1991.

48 Reforma introducida por la Ley No 20.050, de 26 de agosto de 2005.

49 Véase Bulnes Aldunate, L., "La reforma a los contenidos de leyes orgánicas constitucionales”, en XXXV Jornadas Chilenas de Derecho Público, I, Valparaíso, Edeval, 2006, pp. 70-71.

${ }^{50}$ Henríquez (n. 42), p. 63.

51 Véase nota 27.

52 Santamaría (n. 4), p. 322.
} 
es posible que estas materias puedan ser reguladas siguiendo otro procedimiento, como sería el de una ley común u ordinaria. En uno y otro caso, la sanción es la misma: habría una inconstitucionalidad de forma en la ley aprobada, en la medida que no se respetó el procedimiento exigido por la Constitución para regular dichas materias.

En definitiva, no es que un mayor quórum o el establecimiento de mayores exigencias en la aprobación de una ley signifiquen una mutación en el legislador. Este sigue siendo el mismo, cualquiera sea el contenido de la ley que aprueba. Lo que se ve alterado es el procedimiento para dicha aprobación, es decir, no estamos frente a una mutación del sujeto sino del procedimiento, cuyo incumplimiento conlleva la inconstitucionalidad formal de la norma.

Por último, cabe señalar que este principio permite explicar y resolver de mejor forma uno de los problemas que, aplicando de forma estricta el principio de competencia, podría llevar a resultados no del todo razonables. Nos referimos al caso en que una determinada materia sea regulada por una Ley orgánica, siendo que debe ser objeto de Ley de quórum calificado o de ley común ${ }^{53}$. Algunos autores han sostenido que en este caso la ley debe seguir siendo considerada como ordinaria o común, con lo cual se evita un congelamiento del rango, es decir, que a futuro esa materia no pueda ser regulada por ley ordinaria o por decretos con fuerza de ley ${ }^{54}$. Sin embargo, esta solución no guarda coherencia con la aplicación del principio de competencia y es una propuesta que tiende a atenuar un resultado más grave sin fundamento positivo alguno: la Ley orgánica sería inconstitucional por invadir las materias que son propias de un ley ordinaria.

En cambio, la aplicación del principio del procedimiento entrega una respuesta más razonable y coherente a esta cuestión, pues en la medida que se regulen determinadas materias siguiendo un procedimiento más estricto o agravado (Ley orgánica o de quórum calificado), siendo que debían seguir el procedimiento común (Ley ordinaria), es lógico que opere una suerte de absorción, de manera que se entiende que la aplicación de un procedimiento más riguroso o agravado subsume a un procedimiento menos estricto, por lo cual se habrían cumplido en exceso las condiciones formales impuestas por la Constitución para la regulación de determinadas materias. En buenas cuentas, bien se podría afirmar que se estaría aplicando el viejo adagio Ad maiore ad minus.

\subsection{Una división vertical: posibles casos de aplicación del criterio jerárquico}

Una vez que hemos establecido el criterio general para resolver los eventuales conflictos entre los tipos de leyes, nos corresponde analizar si existen algunos casos en que el principio del procedimiento no nos entrega una respuesta adecuada y, por tanto, tendremos que recurrir a los principios tradicionales, especialmente a la jerarquía.

53 El mismo supuesto se presenta en el caso de que una Ley de quórum calificado llegase a regular materias de ley común.

${ }^{54}$ Henríquez (n. 42), p. 70. 
Esta posibilidad ya la hemos planteado en un trabajo anterior y también se ha hecho presente por algunos autores ${ }^{55}$. Básicamente esto se ha centrado en una categoría de ley y en una de las materias que son objeto de Ley Orgánica Constitucional. Me refiero a las Leyes interpretativas de la Constitución y la Ley Orgánica Constitucional de Bases Generales de la Administración del Estado (en adelante LBGAE). Analicemos cada uno de estos casos.

\section{a) Leyes interpretativas y jerarquía constitucional}

La naturaleza y posición que ocupan las leyes interpretativas de la Constitución han sido objeto de algunas reflexiones por parte de nuestra doctrina, no existiendo acuerdo sobre la materia. Por una parte, algunos sostienen que este tipo de leyes podrían proyectar jerarquía respecto de los demás tipos de leyes, imponiéndose en base al principio de jerarquía. Así lo ha planteado Silva Bascuñán, ya que en su opinión se produce una suerte de difuminación del límite entre los ámbitos de competencias del poder constituyente y el poder legislativo, en la medida que la ley interpretativa queda "[...] intelectual y sustancialmente confundida y sumida en la misma Carta Fundamental" 56 . En el mismo sentido se ha pronunciado Cea Egaña, quien caracteriza a la ley interpretativa como una "[...] interpretación auténtica, de carácter general y cuyo contenido se entiende incorporado al Código Político interpretado" 57 , y De la Fuente, quien sostiene que "[...] las leyes interpretativas de la Carta son, entonces, verdaderas leyes en cuanto a su origen, pero también normas constitucionales, en lo que concierne a sus efectos" 58 . Sin embargo, otros autores son de la opinión totalmente contraria, como ocurre con Zúñiga, para quien "[...] la "ley interpretativa" de la Constitución tiene una posición jerárquica de ley, y dado su contenido preceptivo material, es competencialmente limitada (fijar el sentido y alcance de un precepto impreciso, oscuro o falto de claridad, o como dice nuestra jurisprudencia constitucional proporcionar "claridad o precisión" a la redacción de la norma), aunque posee unidad de significado con la norma iusfundamental interpretada, sin que ello pueda importar modificar o alterar la norma iusfundamental" 59 . En este caso, la posición de este autor está matizada por los eventuales peligros que encierra una interpretación que coloque a estas leyes tan cerca de la jerarquía constitucional, lo que en definitiva puede significar el vaciamiento legislativo de la Carta Fundamental bajo

55 Véase Cordero (n. 1), p. 45-46, y De la Fuente, F., "Las funciones legislativa y constituyente en la Constitución de 1980", en Bronfman Vargas, Alan; De la Fuente, Felipe, y Parada Espinoza, Fernando, El Congreso Nacional, Estudio constitucional, legal y reglamentario, Valparaíso, Centro de Estudios y Asistencia Legislativa, 1993, pp. 333-338.

56 Véase Silva Bascuñán (n. 7), pp. 54.

57 Véase Cea Egaña (n. 7), pp. 118-119.

58 Véase De la Fuente (n. 55), p. 335.

59 Véase Zúñiga (n. 13), p. 276. 
el pretexto de la interpretación auténtica, con una posible desconstitucionalización de la misma, abriendo, eventualmente, la puerta al fraude de la Constitución ${ }^{60}$.

Ahora bien, a nuestro parecer resulta difícil tratar de negar el efecto que producen las Leyes interpretativas respecto de las demás normas que integran el ordenamiento jurídico, al punto de que la validez de cada una de éstas va a estar condicionada por el sentido que dicha ley le ha dado a los preceptos de la Carta Fundamental. Creo que es innegable que estamos frente a una relación de supraordenación, pues en caso de conflicto de normas necesariamente deberemos recurrir al principio de jerarquía.

Por otra parte, la preocupación planteada por Zúñiga se diluye al tener presente lo señalado en los apartados anteriores. En primer término, el procedimiento de reforma constitucional ha llegado a identificarse con las exigencias que demanda la Constitución para aprobar una ley interpretativa, al punto que bien se puede sostener que estas leyes se mueven en el piso o mínimo de la reforma constitucional. Por tanto, la preocupación planteada por un posible vaciamiento o desconstitucionalización de la Constitución por la ley interpretativa parece no justificarse ante las exigencias formales que se prevén para su aprobación.

En definitiva, las leyes interpretativas de la Constitución gozan de una sustantividad que las separa de las otras categorías de leyes formales o procedimentales, y las convierte en el ejercicio más básico del poder constituyente con dos elementos que las singularizan: a) tienen la capacidad de imponer su contenido y determinar la validez de todas las normas infraconstitucionales; y b) su función está limitada a determinar el sentido y alcance de preceptos constitucionales oscuros o ambiguos, no pudiendo innovar ni transformarse en un acto de creación de nuevas normas. Es por tal razón que corresponde al Tribunal Constitucional velar porque en su dictación se respete estrictamente la función constitucional que se le ha asignado, conforme a lo establecido en el artículo $93 \mathrm{~N}^{\circ} 1$ de la Carta Fundamental.

\section{b) El caso de la Ley Orgánica Constitucional de Bases Generales y su superlegalidad}

El artículo 38 de la Constitución establece un tipo particular de Ley orgánica, la cual debe regular o determinar "la organización básica de la Administración Pública”, además de garantizar la carrera funcionaria y los principios de carácter técnico y profesional en que deba fundarse. Al efecto, se dictó en el año 1986 la Ley Orgánica Constitucional No 18.575,

${ }^{60}$ Las críticas no se quedan solamente en las ya mencionadas. Este autor sostiene, además, que una posición en tal sentido hace "[...] inútil la potestad constituyente derivada y el procedimiento de reforma constitucional reglado en el Capítulo XV de la Carta Política. Otro peligro asociado estrechamente a los anteriores no menor es el quebranto del principio democrático que está en la base del edificio estatal y del plexo de potestades públicas o normativas, y del cual pende el principio de jerarquía normativa, y el quebranto de la supremacía de la Constitución, al quedar expuesta la Constitución a su desconstitucionalización y fraude expresos". Ídem. p. 277. 
de Bases Generales de la Administración del Estado, actualmente contenida en un texto refundido, coordinado y sistematizado aprobado a través del DFL No 1/2001.

La regulación "básica" de los órganos que integran la Administración del Estado fue propuesta como una forma de superar la heterogeneidad y dispersión de la legislación administrativa vigente en Chile a fines de la década de los 60. Se pensaba que una ley con tales características podría depurar y unificar el régimen jurídico de los servicios públicos, como lo sostuvo la Contraloría General de la República ${ }^{61}$. Esta idea fue retomada por la Comisión Nacional de Reforma Administrativa (CONARA), que en 1974 propone la dictación de una ley básica, equivalente a una verdadera Constitución Administrativa, la cual debía ser desarrollada a través de leyes complementarias, las que sólo se limitarían a aspectos específicos ${ }^{62}$. En definitiva, esta idea se plasmó en la redacción del artículo 38 de la Constitución, tal como entró en vigencia y que, a casi treinta años, se mantiene sin modificación. Por su parte, la redacción de esta Ley orgánica comenzó en el año $1985^{63}$, con un Mensaje del Ejecutivo en el cual se indicaba los propósitos de la misma: "Conviene destacar que las disposiciones del proyecto han servido el propósito del constituyente, en orden a configurar mandatos básicos o esenciales, pero destinados a circunscribir, de un modo efectivo, el campo de acción de la ley común" 64 .

De acuerdo a estos antecedentes, una ley de estas características, esto es, destinada a contener mandatos básicos o esenciales que delimiten o circunscriban el campo de acción de la ley común, debiese ser necesariamente una ley de mayor rango o jerarquía, pues no es posible concebir otra forma de condicionar con sus preceptos la acción del legislador común u ordinario y lograr, en definitiva, unificar los diversos regímenes jurídicos. Por lo demás, así lo entendió la doctrina al poco tiempo de la entrada en vigencia de este cuerpo legal ${ }^{65} \mathrm{y}$, en alguna medida, también aparece en los primeros pronunciamientos

${ }^{61}$ La Contraloría señaló que el método más adecuado sería el de reemplazar la multiplicidad de leyes orgánicas de los servicios públicos por una ley orgánica básica de la Administración del Estado, que contenga las normas fundamentales, la que sería complementada por un conjunto de leyes generales, no por servicios sino por materias. Véase Contraloría General de la República, Memoria, Santiago, 1969, p. 5.

${ }^{62}$ Véase Comisión Nacional de Reforma Administrativa, Ordenamiento jurídico de la Administración del Estado y regionalización del País, Santiago, 1974.

${ }^{63}$ Con anterioridad, la redacción de las Leyes orgánicas fue encomendada a una Comisión de Estudio de Leyes Orgánicas Constitucionales. Esta nombró a su vez una Subcomisión para analizar y hacer una propuesta respecto de la Ley Orgánica de Bases Generales de la Administración del Estado, la que estuvo integrada por Arturo Aylwin Azócar, que la presidió, y los profesores de Derecho Administrativo Manuel Daniel Argandoña, Eduardo Soto Kloss, Osvaldo Oelckers Camus y Pedro Pierry Arrau. A este grupo se integraron Rodrigo de la Cuadra, Olga Feliú Segovia y Juan Guillermo Valenzuela Vargas, Fiscal de ODEPLAN. Sobre los antecedentes de esa ley véase Pierry Arrau, P., "Antecedentes de la Ley de Bases de la Administración del Estado”, en Revista de Derecho, Consejo de Defensa del Estado, No 19, junio 2008, pp. 9-24, y Cordero Quinzacara, E., "La Ley $\mathrm{N}^{\circ} 18.575$ ante la doctrina y jurisprudencia, a 20 años de su entrada en vigencia", en Estudios sobre la Ley Orgánica Constitucional de Bases Generales de la Administración del Estado, Antofagasta, Universidad de Antofagasta, 2008, pp. 9 a 23.

${ }^{64}$ Véase Mensaje Presidencial de 20 de marzo de 1985 (Boletín No 601-06).

${ }^{65}$ En tal sentido, Rolando Pantoja sostuvo que "la jerarquía que una LOC ocupa en el orden de prelación de las fuentes del Derecho, constriñe asimismo al legislador común a respetar sus normas, puesto que la LOC tiene un rango supralegal que la sitúa bajo la CP y sobre la ley simple”. Más aún, sostiene que los mandatos 
del Tribunal Constitucional que considera a las Leyes orgánicas como textos armónicos, sistemáticos y coherentes que desarrollan los preceptos constitucionales y que ocupan un lugar intermedio entre la Constitución y la ley común ${ }^{66}$.

Si bien la jurisprudencia posterior del Tribunal Constitucional ha variado sobre este punto $^{67}$, esto no ha sido así respecto del sentido y función que tiene esta Ley de bases. En esta materia ha mantenido una doctrina constante en el sentido de que toda ley común que contenga disposiciones que no se correspondan con las establecidas en la Ley Orgánica Constitucional No 18.575 , necesariamente deben ser aprobadas como una modificación a dicha ley, es decir, sujeta a un quórum más alto y al control previo obligatorio del Tribunal Constitucional ${ }^{68}$. Con esta doctrina, no exenta de críticas, el Tribunal Constitucional le dio a esta Ley orgánica una suerte de superlegalidad, con el objetivo fundamental de evitar que los preceptos de la Ley de Bases Generales quedaran como letra muerta frente a la acción del legislador común ${ }^{69}$.

de este tipo de leyes producen un efecto vinculante inmediato en el legislador común u ordinario y fijan la línea mediata de horizonte de toda la legislación, arrastrando también al legislador orgánico constitucional por la vía de la consecuencia y coherencia institucionales. "[...] las reglas bases de la LOCBGAE habrán de ser respetadas y desarrolladas, tanto por el legislador de las leyes comunes derivadas que emanan de un mismo texto, cuanto por el legislador de las leyes orgánicas constitucionales que habrán de recaer sobre aspectos orgánicos o funcionales ligados a ella, por tratarse justamente de una Ley Orgánica Constitucional de Bases Generales de la Administración del Estado de Chile”. Véase Pantoja (n. 41), p. 20.

66 Véase Sentencia Rol N ${ }^{\circ}$, de 22 de diciembre de 1981.

67 Véase el apartado destinado al análisis de las leyes orgánicas constitucionales.

${ }^{68}$ Esto fue lo que ocurrió en el caso conocido como "Ley de Pesca", Rol No 115 , de 3 de diciembre de 1990. El proyecto de ley sobre la materia consideraba la creación de un Consejo Nacional de Pesca y cinco Consejos Zonales de Pesca, lo cual no se correspondía con la organización básica prevista en los artículos 24 y 29 de la Ley $\mathrm{N}^{\circ} 18.575$ (actuales artículos 27 y 32). Sin embargo, los mismos preceptos permitían que la ley de forma excepcional estableciera niveles jerárquicos distintos o adicionales, así como denominaciones diferentes (modificación introducida por la Ley $\mathrm{N}^{\circ}$ 18.891). Planteado el requerimiento ante el Tribunal Constitucional, este se encontró ante un claro problema que podía desvirtuar el alcance de la LOCBGAE, en la medida que por la vía de leyes comunes u ordinarias se podía establecer una organización administrativa para los servicios públicos apartándose completamente de lo previsto en dicho cuerpo normativo, privándolo de fuerza normativa. Por tal razón, y a fin de evitar esta suerte de socavamiento o privación de fuerza normativa de la LOCBGAE, estableció que "en la organización de los Ministerios y de los servicios públicos pueden existir organismos con denominaciones distintas a las señaladas en los artículos 24 y 29 de la Ley $\mathrm{N}^{\circ} 18.575$, éstos deben ser creados por ley orgánica constitucional y no por ley común. Si así no fuese ello importaría permitir la delegación de atribuciones a la ley común, lo que transgrediría todo el sistema creado por el artículo 60 de la Carta Fundamental para la determinación del campo de acción de la ley”.

${ }^{69} \mathrm{La}$ interpretación hecha por el Tribunal se aparta claramente del tenor del artículo 38 de la Constitución y sigue en este punto un criterio teleológico, atendiendo al fin y sentido de la norma. En efecto, una ley común que regula la organización, atribuciones, funciones o el régimen de responsabilidad de un servicio público no está estableciendo la organización básica de la Administración del Estado, por tanto no se encuentra en el supuesto del citado artículo 38. Sin embargo, una regulación en tal sentido podría ir en contra de la organización básica establecida por la Ley Orgánica de Bases Generales. En tal caso, una posibilidad es aceptar esta interpretación y, por tanto, socavar el contenido de dicha ley por la vía de la ley ordinaria. La otra posibilidad es la que ha seguido el Tribunal Constitucional, con lo cual entiende que esta Ley orgánica contiene preceptos que están dirigidos al legislador común, de manera que no pueden ser modificados o derogados sino por una Ley orgánica constitucional. Sobre la materia véase la opinión crítica de 
El problema central que plantea esta Ley no sólo está en sus antecedentes, sino en la manera como consagra las normas comunes y, especialmente, aquellas relativas a la organización básica de la Administración del Estado, ya que éstas constituyen verdaderos mandatos al legislador ordinario, como ocurre con sus artículos 27, 30, 32 y 33, en donde se le indican las reglas que debe seguir al momento de crear y organizar internamente un ministerio o un servicio público. Por lo tanto, el Tribunal Constitucional ha mantenido el criterio que se tuvo presente al momento de redactar la norma constitucional y la Ley $\mathrm{N}^{\circ}$ 18.575, y ha optado por una interpretación que evita que a través de una ley simple u ordinaria queden vacías de contenido sus disposiciones. Por lo demás, se debe reconocer que este criterio ha permitido garantizar cierta uniformidad en la regulación de los ministerios y servicios públicos y no constituye una opción interpretativa totalmente alejada de lo dispuesto en artículo 38 de la Constitución, pues el concepto de ley básica contenida en ella se debe entender en relación a otras leyes que deben respetar dichos lineamientos o bases, ya que el Constitución es clara en señalar que la creación y organización de un servicio público debe ser por ley (artículo 64 inc. $4^{\circ}$ ), la que debe respetar el marco fijado por la Constitución y las bases contenidas en una ley orgánica constitucional (artículo 38).

\section{Conclusiones}

La diversidad de tipos legales consagrados en la Constitución de 1980 ha obligado a la doctrina y a la jurisprudencia a buscar la forma como se deben resolver los conflictos normativos que se presentan entre unos y otros al momento de ser aplicados por los operadores jurídicos. Esto implica necesariamente establecer la naturaleza, sentido y función que la Constitución asigna a cada uno de los tipos de leyes en el desarrollo de sus preceptos y en la relación que han de tener con las demás disposiciones que integran nuestro ordenamiento jurídico.

Del análisis de cada uno de los tipos de leyes, se ha podido establecer que la diversificación de los tipos legales responde, por regla general, a razones estrictamente formales o procedimentales, integrando todas ellas parte de un concepto sustantivo de ley destinada a establecer a través de normas generales y obligatorias las bases esenciales de un ordenamiento jurídico. En definitiva, la naturaleza de las Leyes Orgánicas Constitucionales y de quórum calificado no se construye sobre la base de un concepto sustantivo, como en un comienzo lo sostuvo el Tribunal Constitucional, sino en consideración a una diversificación de las materias de ley conforme a su valor relativo, la cual determina distintos procedimientos de elaboración y aprobación.

Zapata Larraín, P., La jurisprudencia del Tribunal Constitucional, Santiago, Corporación Tiempo 2000, 1994, pp. 130-138. Por su parte, hay votos de minoría en varias sentencias del Tribunal Constitucional que siguen este criterio. Véanse Sentencia Rol No 1027, de 24 de enero de 2008; No 1047, de 20 de marzo de 2008; y $\mathrm{N}^{\circ} 1031$, de 20 de mayo de 2008, entre otras. 
En razón de lo anterior, los principios de jerarquía y competencia son insuficientes desde una perspectiva teórico-práctica para resolver las antinomias o conflictos que se pueden presentar entre ellas, tal como se ha tratado de demostrar, porque no dan cuenta o consideran de la naturaleza propia de estos tipos normativos.

Esto conlleva a la formulación de una propuesta centrada en la aplicación del principio de procedimiento como regla general para enfrentar estos casos, lo cual es totalmente coherente con la naturaleza de los tipos de leyes y con la forma como los operadores jurídicos han enfrentado el problema, especialmente el Tribunal Constitucional.

Sin embargo, existen algunos casos de excepción en donde se debe retomar el tradicional principio de jerarquía, en la medida que se rompe con este concepto procedimental de ley y aparece un concepto más sustantivo, como ocurre con las leyes interpretativas de la Constitución y el caso particular de una Ley orgánica, como es la Ley de Bases Generales de la Administración del Estado. En el primer caso, no es posible desconocer la integración que se produce entre la Constitución y la Ley interpretativa, lo cual produce el efecto de proyectar una mayor jerarquía. Además, no se debe olvidar que el procedimiento de aprobación de estas leyes tiene un rango de exigencia que está dentro del nivel exigido para una reforma constitucional. En el segundo caso, la Ley de Bases Generales de la Administración siempre ha reconocido una naturaleza particular, en la medida que buena parte de sus preceptos tienen como destinatario al legislador común. De esta forma, el Tribunal Constitucional ha establecido una suerte de regla de superlegalidad, que hace intangible este cuerpo normativo al legislador ordinario.

\section{BIBLIOGRAFÍA}

Andrade Geywitz, C., Elementos de Derecho constitucional chileno, $2^{\mathrm{a}}$ ed., Santiago, Editorial Jurídica de Chile, 1971.

BASCuñán Rodríguez, A., "El principio de la distribución de competencias como criterio de solución de conflictos de normas jurídicas", en Revista Chilena de Derecho, Número especial, 1998, pp. 33-44.

Bertelsen Repetto, R., "Informe en Derecho", en Revista Chilena de Derecho, vol. 19, № 3 , 1992.

Bronfman Vargas, Alan; De la Fuente, Felipe y Parada Espinoza, Fernando, El Congreso Nacional, Estudio constitucional, legal y reglamentario, Valparaíso, Centro de Estudios y Asistencia Legislativa, 1993.

Bulnes Aldunate, L., "La ley orgánica constitucional", en Revista Chilena de Derecho, vol. 11, Nos. 2-3, 1984.

Bulnes Aldunate, L., "La reforma a los contenidos de leyes orgánicas constitucionales", en XXXV Jornadas Chilenas de Derecho Público, I, Valparaíso, Edeval, 2006.

Bulnes Aldunate, L., "Leyes de base y potestad reglamentaria en la Constitución de 1980", en Revista de Derecho, Universidad Católica de Valparaíso, VI, 1982.

Caldera Delgado, H., "La obsolescencia del concepto de ley del Código Civil y las nuevas relaciones entre la ley y el reglamento a consecuencia de la entrada en vigencia de la Constitución de 1980", en Revista de Derecho y Jurisprudencia y Gaceta de los Tribunales, № 2, T. $82,1985$. 
Caldera Delgado, H., "Ley orgánica constitucional y potestad reglamentaria”, en Revista Chilena de Derecho, vol. 11, Nos. 2-3, 1984.

Cea Egaña, J. L., "Dominio legal y reglamentario en la Constitución de 1980", en Revista Chilena de Derecho, vol. 11, Nos. 2-3, 1984.

Cea Egaña, J. L., Teoría del Gobierno. Derecho Chileno y Comparado. Santiago, Ediciones Universidad Católica de Chile, 2000.

Cordero Quinzacara, E. (coord.), Estudios sobre la Ley Orgánica Constitucional de Bases Generales de la Administración del Estado, Antofagasta, Universidad de Antofagasta.

Cordero Quinzacara, E., "El sentido actual del dominio legal y la potestad reglamentaria", en Revista de Derecho, Pontificia Universidad Católica de Valparaíso, XXXII, Semestre I, 2009.

Cordero Quinzacara, E., "Los principios y reglas que estructuran el ordenamiento jurídico chileno", en Ius et Praxis, vol. 15, No 2, 2009.

De Oтto, I., Derecho constitucional. Sistema de fuentes, $2^{\mathrm{a}}$ ed., Barcelona, Ariel, 1988.

Díez-Picazo, L. M., "Concepto de ley y tipos de ley. ¿Existe una noción unitaria de ley en la Constitución Española?”, en Revista Española de Derecho Constitucional, Año 8, № 24, septiembre-diciembre, 1988.

García de Enterría, E. y Fernández, T. R., Curso de Derecho administrativo, vol. I, $10^{a}$ ed., Madrid, Civitas, 2000.

Garrido Falla, F., Tratado de Derecho administrativo, vol. I, 10 ed., Madrid, Tecnos, 1987.

Garrorena Morales, A. El lugar de la ley en la Constitución española, Madrid, Centro de Estudios Constitucionales, 1980.

Henríquez Viñas, M., Las fuentes formales del derecho, Santiago, LegalPublishing, 2009, pp. 68-69.

Mohor, S. y VARAs, P., "En torno a la Ley orgánica constitucional sobre sistema de inscripciones electorales y Servicio Electoral", en Revista de Derecho, Universidad Católica de Valparaíso, $\mathrm{X}, 1986$.

Nogueira Alcalá, H. y Cumplido Cereceda, F., Instituciones políticas y Teoría Constitucional, T. II, Talca, Editorial Universidad de Talca, 2001.

Pantoja Bauzá, R., Bases generales de la Administración del Estado, Santiago, Ediar Cono-Sur, 1987.

Parejo Alfonso, L. Derecho administrativo, Barcelona, Ariel, 2003, p. 249.

Pierry Arrau, P., "Antecedentes de la Ley de Bases de la Administración del Estado", en Revista de Derecho, Consejo de Defensa del Estado, Nº 19, junio 2008.

Ríos Alvarez, L. "Las leyes orgánicas constitucionales", en Revista Chilena de Derecho, vol. 10, $\mathrm{N}^{\circ} 1$, enero-abril 1983.

Rubio Llorente, F., "Rango de ley, fuerza de ley, valor de ley. Sobre el problema del concepto de ley en la Constitución”, en Revista de Administración Pública, vol. I, N ${ }^{\text {os. }} 100-102$, enerodiciembre, 1983

Santamaría Pastor, J. A., Fundamentos de Derecho administrativo, Madrid, Centro de Estudios Ramón Areces, 1991.

Silva Bascuñán, A., Tratado de Derecho Constitucional, $2^{\text {a }}$ ed. T. VII, Santiago, Editorial Jurídica de Chile, 2000.

Silva Cimma, E., Derecho administrativo chileno y comparado. Introducción y fuentes, Santiago, Editorial Jurídica de Chile, 1996.

Varas Alfonso, P., "El nuevo concepto de ley en la Constitución de 1980", en Revista Chilena de Derecho de la Facultad de Derecho de la Pontificia Universidad Católica de Chile, vol. 11, $\mathrm{N}^{\text {os. }}$ 2-3, 1984. 
Vivanco A., Curso de Derecho Constitucional, T. I, Santiago, Ediciones Universidad Católica de Chile, 2007.

Zapata Larraín, P., La jurisprudencia del Tribunal Constitucional, Santiago, Corporación Tiempo 2000, 1994.

ZúÑiga Urbina, F., "Concepto de ley y tipos de ley. Notas acerca de jerarquía y competencia”, en Revista de Derecho, Universidad Católica de Valparaíso, XVIII, 1997.

ZúÑIga Urbina, F., "Constitución y ley interpretativa. Algunas notas sobre una paradoja y peligros relativos a este tipo de ley", en Ius et Praxis, vol. 15, No 2, 2009. 
